\title{
NUMERICAL SIMULATION OF MID-INFRARED DOUBLE HETEROSTRUCTURES LASER BASED ON InAsSb/InAsSbP MATERIAL SYSTEM
}

\author{
Sanjeev Tyagi \\ Department of Electronics and Instrumentation Engg. \\ MJP Rohilkhand University, Bareilly (UP) 243006 India
}

\begin{abstract}
The numerical simulation of a double heterostructures (DH) laser diode based on $\mathbf{n}^{+}$-

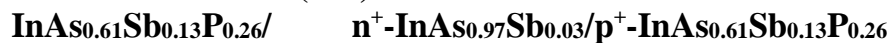
material system has been carried out in this paper. The proposed structure is suitable for use as a source for free space optical communication system at $3.7 \mu \mathrm{m}$ at room temperature. The laser has been characterized in terms of several laser parameters like energy band diagram and doping profile. The current-voltage characteristics of structure have been estimated taking into account the degeneracy effect. The output power of the laser has been estimated by solving the applicable Helmholtz equation for the trial structure. The outcomes of the numerical simulation have been validated by the reported experimental results.
\end{abstract}

Keywords - ATLAS, Double Hetrostructure Laser, Midinfrared, Numerical simulation

\section{INTRODUCTION}

There are number of low absorption atmospheric windows (2-2.5 $\mu \mathrm{m}$ and 3.5-4 $\mu \mathrm{m}$ ) in the mid-infrared (MIR) spectral region enabling one to setup free space optical communication link [1,2]. The advantages of the free space optical communication includes high bandwidth, eye safe operation, license free service, high transmission security, protocol transparency, jam-proof and error free link [1]. The sources for free space optical communication system require narrow bandgap semiconductor materials for their fabrication [3]. The $\mathrm{InAs}_{1-\mathrm{x}} \mathrm{Sb}_{\mathrm{x}} / \mathrm{InAs}_{1-\mathrm{x}-\mathrm{y}} \mathrm{Sb}_{\mathrm{x}} \mathrm{P}_{\mathrm{y}}$ semiconductor alloys are very promising material system for the design and fabrication of high power mid-infrared lasers with the emission wavelength in mid-infrared region. This material system provides a very favorable condition for the carrier and optical confinement due to its type-I band alignment $[3,4]$. It is expected that free space optical communication links in MIR can offer higher bandwidth and better selectivity of receivers as compared to their conventional microwave communication counterparts.

\section{THE DEVICE STRUCTURE}

The device under consideration is based on $\mathrm{N}^{+}$ $\operatorname{In} \mathrm{As}_{0.61} \mathrm{Sb}_{0.13} \mathrm{P}_{0.26} / \quad \mathrm{n}^{0}-\mathrm{InAs}_{0.97} \mathrm{Sb}_{0.03} / \quad \mathrm{P}^{+}-\operatorname{InAs}_{0.61} \mathrm{Sb}_{0.13} \mathrm{P}_{0.26}$

\author{
Sundar Singh \\ Department of Physics \\ Bareilly College, Bareilly (UP) 243005 India
}

semiconductor material system similar to one reported by Yin et al. $[5,6]$. The schematic of the structure is shown in the Fig 1. The structure consists of two confining layers of larger bandgap degenerate quaternary materials $\operatorname{In} \mathrm{As}_{0.61} \mathrm{Sb}_{0.13} \mathrm{P}_{0.26}$ of different conductivities and an active layer of $\operatorname{InAs}_{0.97} \mathrm{Sb}_{0.03}$ sandwitched between them to form the double heterostructure. The whole structure is supposed to be grown on the lattice matched p-InAs substrate. The proposed ideal DH laser structure forms a Type-I band alignment [4]. The DH laser structure is designed in a way so as to emit near $3.7 \mu \mathrm{m}$ at $300 \mathrm{~K}$ coinciding with the one of the low loss atmospheric windows suitable for free space optical communication.

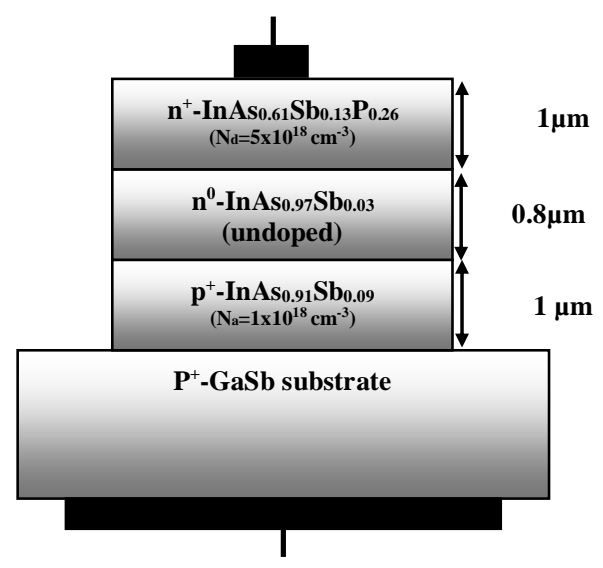

Fig. 1. Schematic of the proposed laser structure

The compositional and temperature dependent energy bandgap $\left(\mathrm{E}_{\mathrm{g} 2}\right)$ of In $\mathrm{As}_{1-\mathrm{x}} \mathrm{Sb}_{\mathrm{x}}$ has been calculated using [7]

$E_{g 2}(x, T)=0.411-\frac{3.4 \times 10^{-4} T^{2}}{210+T}-0.876 x+0.70 x^{2}+3.4 \times 10^{-4} x T(1-x)$

where $\mathrm{x}$ is the mole-fraction $(=0.03$ in our model $)$ and $\mathrm{T}$ is the temperature in Kelvin.

On the other hand, to the first approximation, the composition dependence of the energy bandgap $\left(E_{g 1}\right)$ of InAs $\mathrm{Sb}_{\mathrm{y}} \mathrm{P}_{1-\mathrm{x}-\mathrm{y}}$ at room temperature can be expressed as [8] 
$E_{g 1}=x E_{g}(\operatorname{In} A s)+y E_{g}(\operatorname{InS} b)+(1-x-y) *$

$E_{g}(\operatorname{In} P)-y(1-x-y) C_{2}-x(1-x-y) C_{1}-x y C_{3}$

where $C_{1}, C_{2}$ and $C_{3}$ are the appropriate bowing parameters for InAs, InSb and InP and $E_{g}(\operatorname{InAs}), E_{g}(\operatorname{InSb})$ and $E_{g}(\operatorname{InP})$ are the energy bandgap values of InAs, InSb and InP binary semiconductors respectively at room temperature and taken from [9, 10]. The other parameters of quaternary materials (InAsSbP) used in the simulation model have been computed from the parameters of the constituent binary and ternary materials using the linear interpolation technique and same have been incorporated into the simulation codes of ATLAS [11].

\section{NUMERICAL SIMULATION MODEL}

The structure has been simulated in the Deckbuild platform of ATLAS [10] by defining mesh, region, electrode and doping parameters as listed in Table-1 alongwith other parameters. In the material statement, several material parameters like bandgap, permittivity, density of state of conduction and valance band, mobility and carrier lifetimes value have been provided as per our structure and estimation.

The current-voltage characteristics of the structure have been determined with the help of ATLAS simulation tool by solving the governing charge equation using initial solution statement in the Deckbuild coding by considering the FERMIDIRAC statistics applicable for highly doped degenerate semiconductors. The doping profile, electric field profile, electron-hole concentration under equilibrium and current-voltage characteristics have been plotted using the TONYPLOT tool of ATLAS.

\section{RESULTS AND DISCUSSIONS}

The numerical computation using ATLAS device simulation software has been carried out for mid-infrared $\mathrm{P}^{+}$InAs ${ }_{0.61} \mathrm{Sb}_{0.13} \mathrm{P}_{0.26} / \mathrm{n}^{0}-\mathrm{InAs}_{0.97} \mathrm{Sb}_{0.03} / \quad \mathrm{N}^{-}-\mathrm{InAs}_{0.61} \mathrm{Sb}_{0.13} \mathrm{P}_{0.26}$ double heterostructures laser at $300 \mathrm{~K}$. The various material parameters used in the simulation model are taken from [5, 9]. Fig. 2 depicts the doping profiles in various layers of the structure under consideration. The $\mathrm{P}^{+}$region is considered to be heavily doped to $10^{18} / \mathrm{cm}^{3}, \mathrm{n}^{+}$region doped to $5 \times 10^{18} / \mathrm{cm}^{3}$. The doping concentration in the unintentionally doped intrinsic region is considered to be $10^{16} / \mathrm{cm}^{3}$.

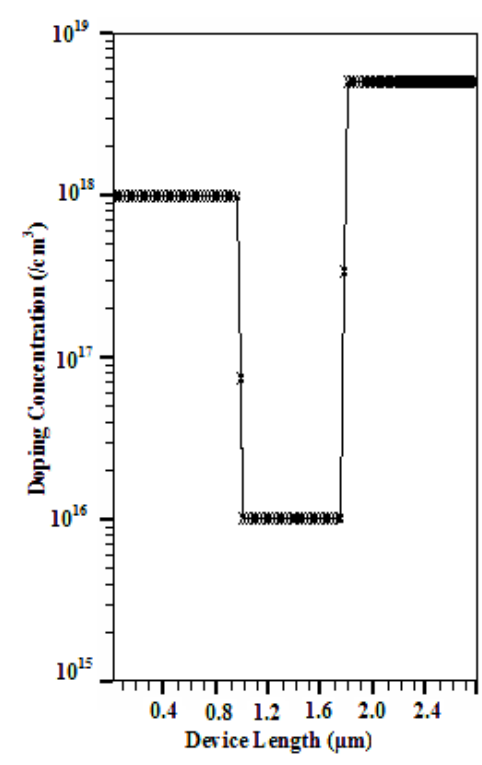

Fig. 2. Doping profile along the structure

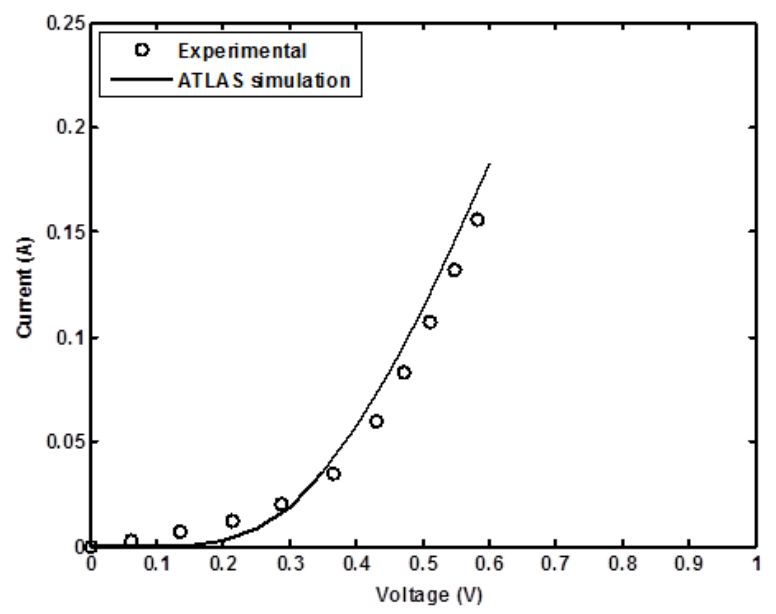

Fig. 3. The current-voltage characteristics of the structure

The current-voltage characteristics obtained on the basis of ATLAS simulation are compared and contrasted with the experimentally values reported by others on the same structure at $100 \mathrm{~K}[5,6]$ and is shown in Fig $3[5,12]$. It can be easily seen that there is a very good agreement between the simulated results and those reported by others. It is further seen that the deviation between the two results increase at higher bias voltage. This is attributed to the fact that at higher bias voltage a larger injection of carriers causes changes of various parameters due to the change of junction temperature. The temperature dependence of these parameters is not modeled in the present simulation. The current-voltage data of the same structure is tabulated in Table 1. The Table 1 also depicts the variation of normalized optical output power with bias current density of the laser structure. There is a good agreement between the results obtained on the basis of ATLAS simulation and experimental results reported for the 


\section{International Journal of Engineering Applied Sciences and Technology, 2019 \\ Vol. 4, Issue 8, ISSN No. 2455-2143, Pages 165-167 \\ Published Online December 2019 in IJEAST (http://www.ijeast.com)}

same structure by Yin et al [5]. A larger departure of the simulated results from the experimentally measured values is attributed to the factors mentioned before. It may be further pointed out that in the simulation the effect of interface charges have been completely neglected.

Table - 1 Comparison of ATLAS simulation results and reported experimental results for MIR Laser structure

\begin{tabular}{|c|c|c|c|c|c|}
\hline \multirow[t]{2}{*}{$\begin{array}{l}\text { Voltage } \\
\text { (V) }\end{array}$} & \multicolumn{2}{|c|}{ Current (A) } & \multirow{2}{*}{$\begin{array}{l}\text { Bias } \\
\text { Current } \\
\text { density } \mathbf{J} \\
\left(\mathbf{A} / \mathbf{c m}^{2}\right)\end{array}$} & \multicolumn{2}{|c|}{$\begin{array}{c}\text { Normalised } \\
\text { Output Power } \\
\end{array}$} \\
\hline & $\begin{array}{l}\text { ATLAS } \\
\text { Model }\end{array}$ & $\begin{array}{l}\text { Reported } \\
\text { Experime } \\
\text { ntal }\end{array}$ & & $\begin{array}{l}\text { ATLAS } \\
\text { Model }\end{array}$ & $\begin{array}{l}\text { Reporte } \\
\mathrm{d} \\
\text { Experi } \\
\text { mental }\end{array}$ \\
\hline 0.10 & $3.4 \times 10^{-9}$ & $4.8 \times 10^{-9}$ & 1200 & 0.048 & 0.049 \\
\hline 0.25 & $4.7 \times 10^{-5}$ & $5.8 \times 10^{-5}$ & 1500 & 0.34 & 0.34 \\
\hline & & & 1800 & 0.79 & 0.80 \\
\hline
\end{tabular}

\section{CONCLUSION}

The DH-laser structure have been simulated using ATLAS device simulation package in terms of the energy band diagram, net doping profile, current-voltage characteristics and output power. The degeneracy effect has been considered for calculating the current-voltage characteristics. The results of the ATLAS simulation studies are found to be in good agreement with the experimental results reported by others, which ensures the validity of our model. It is expected that model developed for the structure, can be used for improving and optimizing the existing structures and development of efficient device prototypes.

\section{REFERENCE}

[1] Prasad N. S. (2005), 'Optical Communication in the midwave IR spectral band', J. Opt. Fiber Commun. Rep. Vol. 2, pp. 558-602

[2] Danilova A. P., Imenkov A. N., Kolchanova N. M., Civis S., Sherstnev V. V., and Yakovlev Yu. P. (2000), 'Singlemode InAsSb/InAsSbP laser $(\mu=3.2 \mu \mathrm{m})$ tunable over $100 \AA ̊$ ', Semiconductor Vol. 34 No. 2, pp. 237-242.

[3] Ashley T. (2001), 'Type-I InSb-based mid-infrared diode lasers', Phil. Trans. R. Soc. Lond. A, Vol. 359, pp.475488.

[4] Sharma B.L. and Purohit R.K. (1974), 'Semiconductor heterojunction', Pergamon Press, Oxford

[5] Yin M., Krier A., Krier S., Jones R. and Carrington P. (2006), 'Mid-infrared diode lasers for free space communication’ Proc. SPIE Vol. 6399, pp. 63990C1-C6

[6] Yin M., Krier A., Carrington P.J., Jones R. and Krier S.E. (2007), 'Diode laser for free space optical communication based on InAsSb/InAsSbP grown by LPE', Proc. $8^{\text {th }}$ International Conference on Mid-Infrared
Optoelectronics: Materials and Devices (MIOMD-VIII), Bad Ischl, Austria, pp. 140-141

[7] Rogalski A., Adamiec K. and Rutkowski J. (2000), 'Narrow-gap semicopnductor photodiode', SPIE Press, Bellingham, USA

[8] Gertner, E.R., Cheung, D.T., Andrews, A.M. and Longo, J.T. (1977), 'Liquid phase epitaxial growth of InAs $\mathrm{Sb}_{\mathrm{y}} \mathrm{P}_{1 \text {. }}$, x-y layers on InAs', J. Electron. Mater. Vol. 6, pp. 163 172.

[9] Levinshtein, M., Rumyantsev S., Shur, M. (1996) 'Handbook Series on Semiconductor Parameters Vol. 2, World Scientific, Singapore.

[10] Vurgaftman I. and Meyer J.R. (2001), 'Band parameters for III-V compound semiconductors and their alloys', Appl. Phys. Lett. Vol. 89, No. 11, pp. 5815-5817.

[11] Silvaco Inc. (2005), 'ATLAS user's manual-A device simulator software', www.silvaco.com.

[12] Sanjeev and Chakrabarti P. (2014), 'ATLAS simulation of a laser diode for free space optical communication (FSOC) in mid-infrared spectral region', Opto-Electron. Rev., Vol. 22, no.3, pp. 147-151. 